\title{
91. On the Effect of Light on the Mating of the Rice Borer, Chilo simplex Butler.
}

By Tokio KABURAKI and Shohei KuRIHARA.

Zoological Institute, Faculty of Agriculture, Tokyo Imperial University.

(Comm. by C. SaSAKI, M.I.A., July 12, 1932.)

In this brief account a record is given of results obtained by experiments which were carried out with a view to determining the effect of light on the mating of the rice borer, Chilo simplex Butler. As the source of light was employed electric-light lamp of A 60 [100 V., $30 \mathrm{~W}$. and 295 lumen ( 23.5 c.p.) ], which was placed at one end of the dark room. Extending to positions seven meters apart from the source of light, at intervals of one meter, were arranged glass jars containing moths which emerged shortly before tests. As controls were used blackened glass jars. The number of males and females subject to tests amounts to 65 respectively in each lot. The experiments were carried out, extending from June 28 to July 4, during which period the temperature was on the average $24.4^{\circ} \mathrm{C}$, with a maximum of $25.6^{\circ} \mathrm{C}$ and a minimum of $23.7^{\circ} \mathrm{C}$, and the humidity was on the average $81.9 \%$, with a maximum of $92.7 \%$ and a minimum of $76.6 \%$.

The Iuminosity in each lot was measured as in the following table.

\begin{tabular}{c|c|c|c|c|c|c|c}
\hline $\begin{array}{c}\text { No. of lots } \\
\text { (Distance in meter from } \\
\text { the source of light) }\end{array}$ & 1 & 2 & 3 & 4 & 5 & 6 & 7 \\
\hline $\begin{array}{c}\text { Luminosity } \\
\text { (lux) }\end{array}$ & 24.0 & 6.3 & 2.9 & 1.7 & 1.0 & 0.7 & 0.5 \\
\hline
\end{tabular}

N.B. Electromotive force at the time of measurement was 96 volt; that in the course of tests ranged from 95 to 105 volt.

As is well known, the luminosity $(L)$ is inversely proportionate to the square of distance $(r)$; that is,

Accordingly, $\quad L=\frac{C_{1}}{r^{2}} \quad$ or $\quad C_{1}=L r^{2}$.

$$
\begin{aligned}
& L \infty \frac{1}{r^{2}} \cdot \\
& \quad \text { or } \quad C_{1}=L r^{2} .
\end{aligned}
$$

This is a part of investigations carried out under the auspices of the Department of Agriculture and Forestry. 
Making use of the observed values given in the table, the constant $C_{1}$ was computed; namely,

$$
C_{1}=25.3 \pm 0.27 \text { (p. e.). }
$$

Therefore :

$$
L=\frac{25.3}{r^{2}} \text {. }
$$

Consequently it is clear that this equation represents fairly well the observed quantities in the table.

Now examining the percentage of mating, we obtained the results, as in the following table.

\begin{tabular}{c|c|c|c|c|c|c|c|c}
\hline No. of lots & 1 & 2 & 3 & 4 & 5 & 6 & 7 & Control \\
\hline $\begin{array}{c}\text { Percentage of } \\
\text { mating }\end{array}$ & 5.7 & 17.1 & 25.7 & 27.1 & 44.3 & 50.0 & 45.7 & 45.7 \\
\hline
\end{tabular}

So far as tests are concerned, the percentage of mating $(x)$ appears to be proportionate to the distance $(r)$ from the source of light; namely, $x \sim r$.

Hence $\quad x=C_{2} r$ or $\quad C_{2}=\frac{x}{r}$.

Computing the constant $C_{2}$ with the observed values given in the table, we obtained $\quad C_{2}=7.62 \pm 0.32$ (p.e).

Therefore : $\quad x=7.62 r$ \pm 0.32 (p. e.)

This equation represents fairly well the relation between the distance and the percentage of mating, as is seen in Text-fig. 1.

Subsequently, examining the time which goes on from the beginning of test to mating, the results as given in the following table were obtained.

\begin{tabular}{c|c|c|c|c|c|c|c|c|}
\hline No. of lots & 1 & 2 & 3 & 4 & 5 & 6 & 7 & Control \\
\hline $\begin{array}{c}\text { Time which went } \\
\text { on from the } \\
\text { beginning of } \\
\text { test to mating }\end{array}$ & 2.35 & 1.03 & 0.50 & 0.47 & 0.38 & 0.35 & 0.32 & 0.22 \\
\hline
\end{tabular}

Glancing over this table, it is self-evident that there exists the following relation between the distance $(r)$ from the source of light and the time $(t)$ which went on from the beginning of test to mating.

$$
t \infty \frac{1}{x^{m}}
$$


Accordingly, $\quad t=\frac{C_{3}}{r^{m}}$.

For the sake of convenience, this equation is now transformed into the form: $\quad \log _{10} t+m \log _{10} r=\log _{10} C_{33}$.

Putting $\quad \log _{10} C_{3}=K$,

$$
K-m \log _{10} r=\log _{10} t .
$$

As $r$ and $t$ are known quantities, $K$ and $m$ can be determined by the method of least square as follows:

$$
\begin{array}{ll} 
& K=+0.316 \pm 0.038 \text { (p. e.) } \\
\text { or } \quad & C_{3}=2.07 \pm 0.18 \text { (p. e.) } \\
& m=+1.03 \pm 0.064 \text { (p. e.) } .
\end{array}
$$

As $m$ is here regarded as almost equal to 1 ,
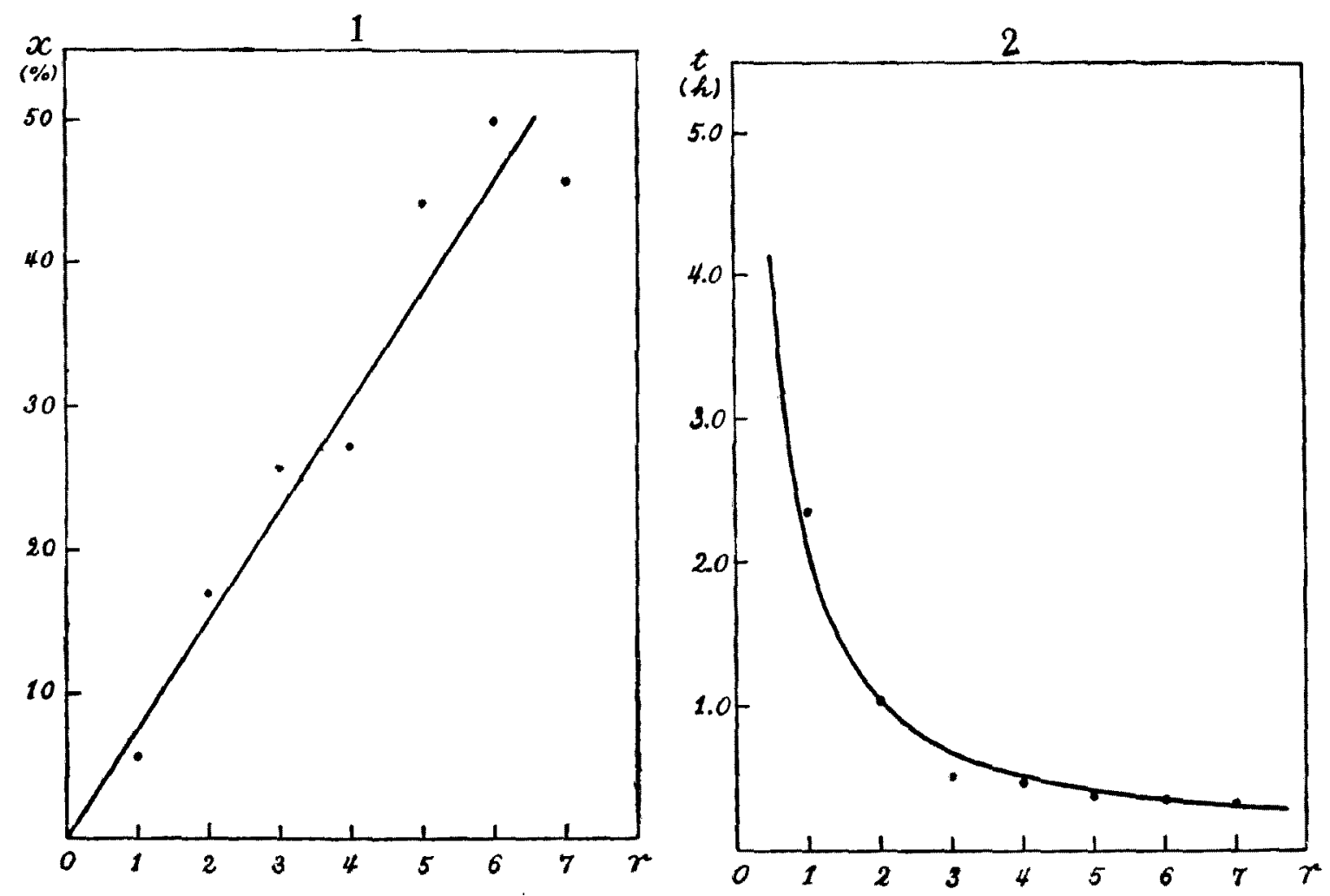

Text-fig. 1. Diagram showing the relation between the distance $(r)$ from the source of light and the percentage of mating $(x)$. The full line represents the equation $x=7.62 r$, and the dots denote the observed values.

Text-fig. 2. Diagram showing the relation between the distance $(r)$ from the source of light and the time $(t)$ which went on from the beginning of test to mating. The full line represents the equation $t=\frac{2.07}{r}$, and the dots denote the values actually observed. 


$$
t=\frac{2.07}{r} \text {. }
$$

This equation represents fairly well the relation between the distance and the time, as is seen in Text-fig. 2 .

Now let us pass on to summarize the above mentioned relations; that is,
1) $L \infty \frac{1}{r^{2}}$,
2) $x \infty r$,
3) $t \propto \frac{1}{r}$.

As $x$ and $t$ are in fact dependent upon $L$, it can be said as follows:

$$
\begin{aligned}
& x \propto L^{-\frac{1}{2}}, \\
& t \infty L^{\frac{1}{2}} .
\end{aligned}
$$

Generally speaking, the percentage of mating is inversely proportionate to the square-root of luminosity, and the time which goes on from the beginning of test to mating is proportionate to the square-root of luminosity.

According to experiments conducted by Mr. Iwasa, the percentage of egg-laying appears to be of a tendency closely similar to the case with the percentage of mating. 